\title{
Speeding Towards the Goal That We Set Out
}

After $1 \frac{1}{2}$ years of existence of Mediators of Inflammation there is a $40 \%$ increase in manuscript submissions. The performance of the Journal is such that it is now included in Chemical Abstracts, Excerpta Medica (EMBASE) and is listed in Current Contents. All this is largely due to the occurrence of three circumstances: (a) timely topics of the submitted articles; (b) high standard of the published papers; (c) rapidity of the review process and the short time from acceptance to publication.

However there is no room for complacency. Hence the call-for-papers continues to be our slogan. Further, if you find as a reader that our Journal delivers important data to the scientific community, please urge your librarian to subscribe, thus im- proving the dissemination of the information and thereby letting other colleagues profit from the papers we are publishing.

When the Journal was launched, we set out to be the most rapid prime forum of choice within the field. We are approaching that goal, but have not yet reached it. On behalf of my colleague Editors and members of the Editorial Board, we encourage you to help us in realizing that, Mediators of Inflammation obtains amongst scientific journals the place which it deserves.
Iván L. Bonta

Editor-in-Chief 


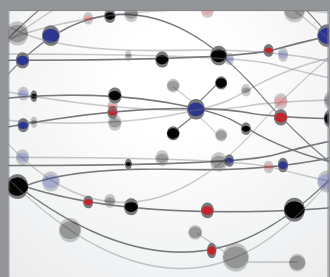

The Scientific World Journal
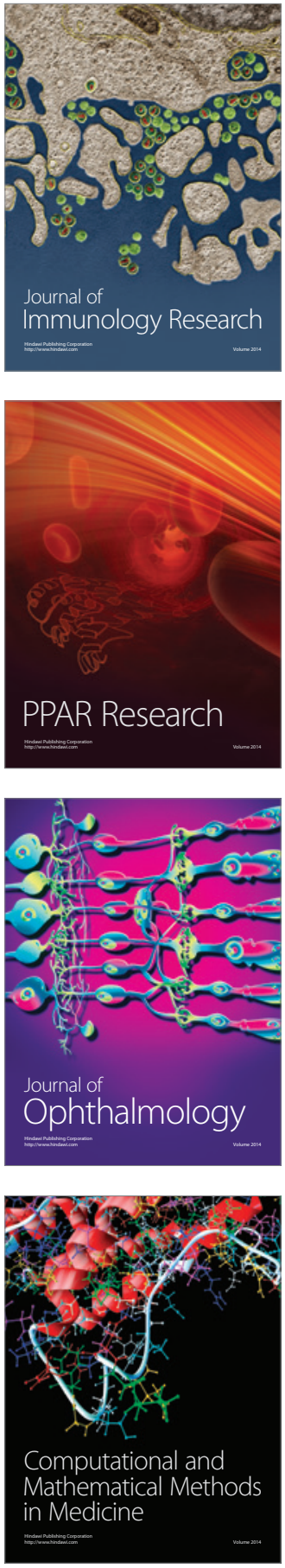

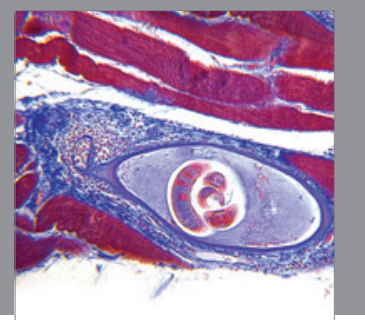

Gastroenterology

Research and Practice
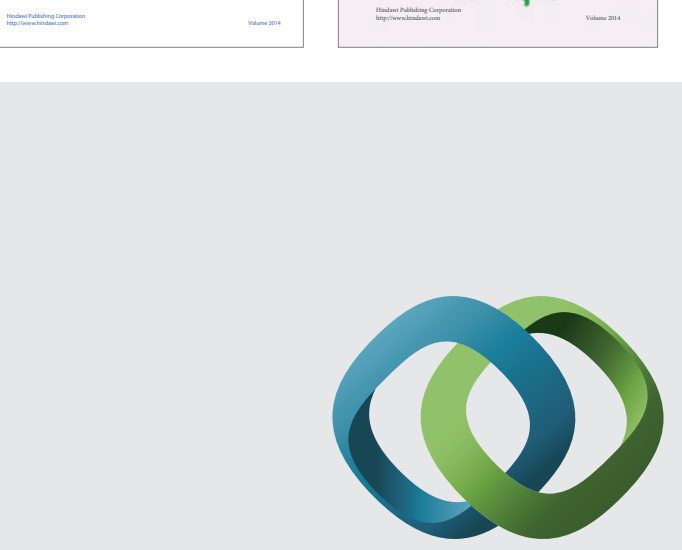

\section{Hindawi}

Submit your manuscripts at

http://www.hindawi.com
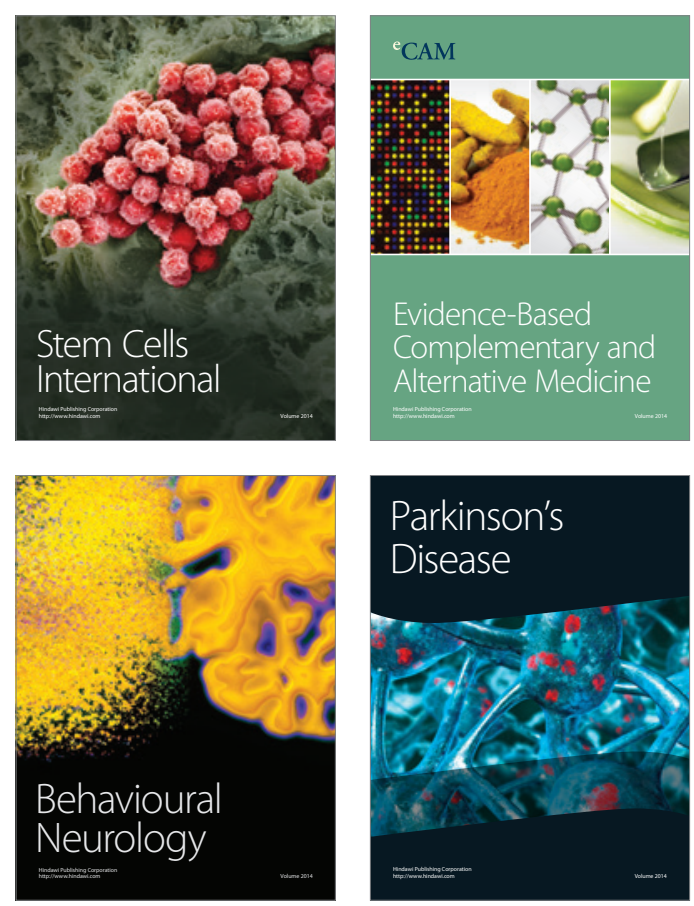

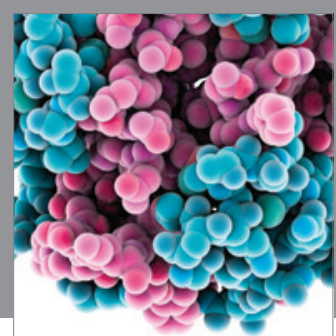

Journal of
Diabetes Research

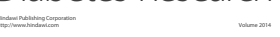

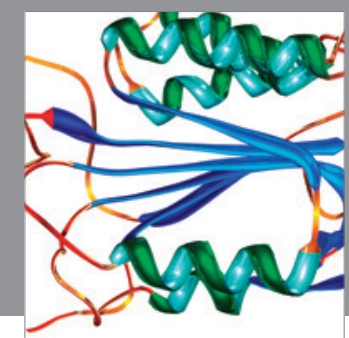

Disease Markers
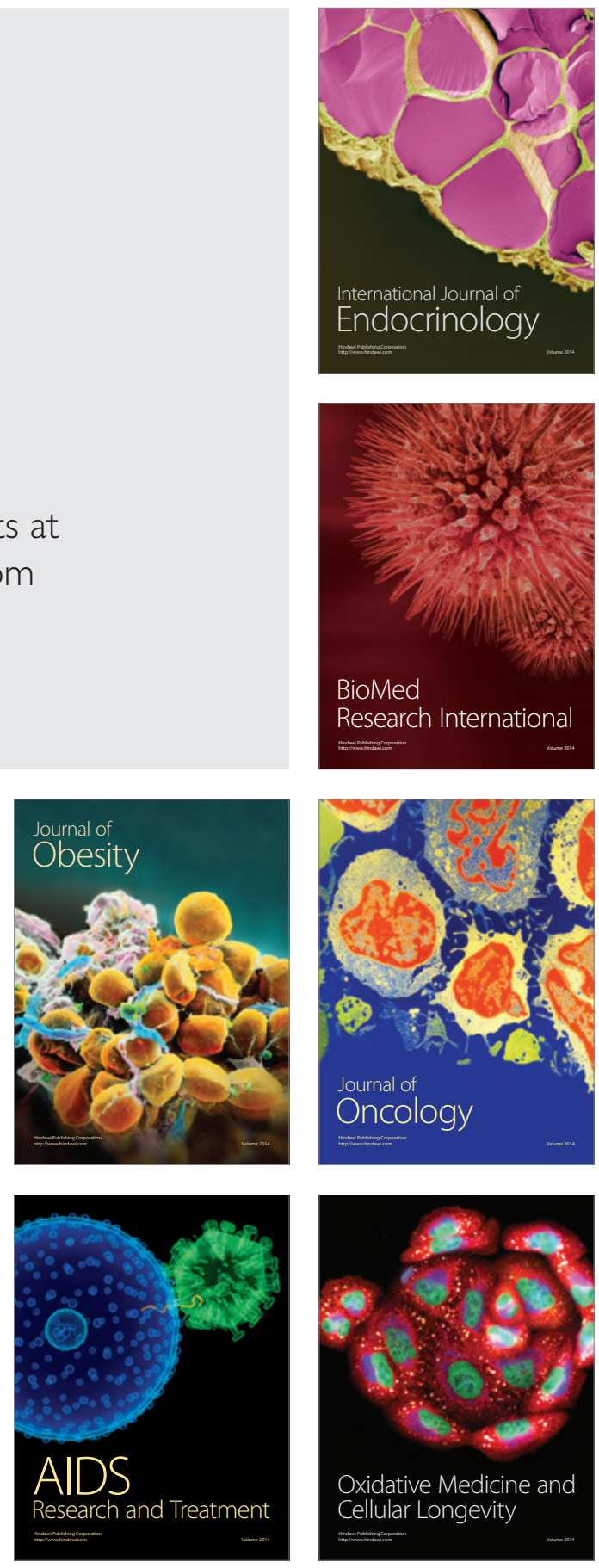